\title{
Laparoscopic Evaluation of Primary and Secondary Subfertility
}

\author{
SETARA BINTE KASEM ${ }^{1}$, NILUFER SULTANA ${ }^{2}$, FERDOUSI BEGUM ${ }^{3}$, \\ SHAIKH ABDUR RAZZAQUE ${ }^{4}$, RAISAADIBA ${ }^{5}$, SELMAANIKA ${ }^{6}$
}

\begin{abstract}
:
Background: Prevalence of subfertility in industrialized countries has been quoted as $20 \%$, and seems to be on the rise. Traditional way to assess the uterine cavity, tubal structure and tubal patency was hysterosalphingography but it is now been largely superseded by laparoscopy and hysteroscopy. With the objective of this study was to highlight the role of laparoscopy in establishing the diagnosis of primary and secondary female subfertility and different therapeutic procedure done.
\end{abstract}

Method: This cross sectional study was conducted in the Subfertility and Reproductive Medicine Unit of Gynae and Obstetrics department of Dhaka Medical College Hospital, Dhaka from January 2015 to June 2018. Total 4256 sub fertile patients attended the Infertility OPD. Out of these 215 patients were selected for laparoscopy. Those patients who had contraindication for laparoscopy were excluded from study. Detailed laparoscopic findings were recorded.

Results: Out of 125 selected sub fertile patients 136 (63.26\%) patients were in primary subfertility group while 79 (36.74\%) patients were in secondary subfertility group. In primary subfertility group( $n=136)$, most common laparoscopic finding was PCO in $44(32.34 \%)$ patients followed by peritubal and periovarian adhesions in 24 (17.65\%) patients, Bilateral tubal block in 23(16.91\%) patients, Endometriosis in 15(11.03\%), Unusual tortuous and lengthy tube in 15(11.03\%) patients, fibroid in 11(8.09\%) patients, Mullerian agenesis and hypoplasia in $3(2.21 \%)$ cases. No visible abnormality found in $22(16.18 \%)$ cases.

The commonest finding by laparoscopy in patients with secondary infertility were PCO in 18 (22.78\%) patients and peritubal and periovarian adhesions in $18(22.78 \%)$ patients, followed by Bilateral tubal block in 12(15.19\%) patients, fibroid uterus in 12(15.19\%) patients, Endometriosis in 10(12.66\%), Genital tuberculosis in 3(1.40\%) cases. No visible abnormality found in 12(15.19\%) cases.

Various laparoscopic procedure like Ovarian drilling. Adhesiolysis, ovarian cystectomy, cyst puncture, salphingostomy, Myomectomy.

Conclusion: Laparoscopy helped us to detect and treat important clinical condition in bath primary \& secondary sub fertility.

\section{Introduction:}

Infertility is a problem of global proportions, worldwide more than 70 million couples suffer from infertility ${ }^{1}$. Prevalence of subfertility in industrialized countries has been quoted as $20 \%$, and seems to be on the rise $^{2}$. Infertility leads to considerable personal suffering and disruption of family life ${ }^{3}$. Diagnostic evaluation for infertility is indicated for women who

1. Designation-Associate Professor (Gynae \& Obstetrics), Dhaka Medical College.

2. Professor \& Head of department (Gynae \& Obstetrics), Dhaka Medical College

3. Professor \& Head of department (Gynae \& Obstetrics), Ibrahim Medical College

4. Professor (Paediatrics Cardiology), National institute of Cardiovascular diseases.

5. Honarory Medical Officer, Dhaka Medical College

6. Fifth Year Student, Bangladesh Medical College.

Address of Correspondence: Dr. Setara Binte Kasem, Associate Professor (Gynae and Obstetrics), Dhaka Medical College. Mob-01552314895, Email: dr.setaraa@gmail.com. 
failed to achieve a successful pregnancy after 12 months or more of regular unprotected intercourse. Since approximately $85 \%$ of couples may be expected to achieve pregnancy within that time interval without medical assistance, evaluation may be indicated for as many as $15 \%$ of couples ${ }^{3}$.

The causes of infertility are broadly classified as male factors, female factors and unknown or combined ${ }^{4}$. About $25-40 \%$ of cases of infertility are attributed to male factor ${ }^{2}$. During the investigations in the female it is mandatory to rule out the pathology of the genital tract.

Diagnostic laparoscopy is generally not a part of initial infertility evaluation; however, number of reports have shown that it is effective procedure for evaluation of long term infertility ${ }^{1}$.

Laparoscopy provides information regarding tubal and ovarian status, uterine normality and standard means of diagnosing various pelvic pathologies eg: Pelvic inflammatory Disease, Endometriosis, Pelvic congestion and tuberculosis ${ }^{1}$ Besides this it is the most useful method of assessment of tubal patency ${ }^{1}$. An accurate diagnosis is the key to successful treatment ${ }^{1}$.

After normal hysterosalphingography, laparoscopy reveals abnormal findings in $21.68 \%$ cases of infertile couples. Untreated pelvic inflammatory disease, postabortal, postpartum infection and tuberculosis are common factors of infertility in developing countries ${ }^{1}$.

Currently, laparoscopy is perceived as a minimally invasive surgical technique that both provides a panaromic and magnified view of the pelvic organs and allows surgery at the time of diagnosis. Laparoscopy has become an integral part of gynecologic surgery for the diagnosis and treatment of abdominal and pelvic disorders of the female reproductive organs ${ }^{5}$.

This study was carried out to determine different causes of female infertility and their comparative frequency in patients with primary and secondary infertility on diagnostic laparoscopy and different therapeutic procedure done at the study centre.

\section{Materials and Methods:}

A cross sectional study was undertaken among married sub fertile women in Female Subfertility and Reproductive Medicine Unit of Gynae and Obstetrics department of Dhaka Medical College Hospital,
Dhaka from January 2015 to June 2018. Total 4256 subfertile patients attended the Infertility OPD. Out of these 215 patients were selected for laparoscopy. Those patients who had contraindication for laparoscopy were excluded from study. All the patients were councelled regarding laparoscopy and indication of laparoscopy.

Inclusion criteria were primary infertility and secondary infertility

Exclusion Criteria were couple who had not lived together for at least 12 months and patient with absolute or relative contraindication for laparoscopy eg: any preexisting cardiovascular or respiratory condition, generalized peritonitis, intestinal ileus or obstruction and abdominal hernia.

A complete relevant history and clinical examination was carried out. A complete hormone profile including $\mathrm{FSH}$, LH, prolactin, progesteron, testosteron, TSH, Abdominal ultrasonogram was done. Informed written consent was taken from every patient. Under GA per speculum and pervaginal examination was done in every patient. Detailed laparoscopic findings were recorded. Tubal testing was done by injecting methylene blue in all the cases. D\&C was carried out and endometrium was sent for histopathlogy.

\section{Results:}

Out of 4256 subfertile patients total 215 patients were selected for laparoscopy. 136 (63.26\%) patients were in primary subfertility group while 79 (36.74\%) patients were in secondary subfertility group. Age range among primary subfertility group were 56 $(41.18 \%)$ patients were between 18 to 25 years, 70 $(51.47 \%)$ patients were between 26 to 35 years, 10 $(7.35 \% \%)$ patients were more than 35 years. Age range among secondary subfertility group 17 $(21.52 \%)$ patients were between 18 to 25 years, 52 $(65.82 \%)$ patients were between 26 to 35 years and $10(12.66 \%)$ patients were more than 35 years (Table-I).

No visible abnormality were seen in $34(15.81 \%)$ patients (Table-II). Among them 22 (16.18\%) women were suffering from primary subfertility and 12 $(15.19 \%)$ from secondary subfertility. Most common laparoscopic findings were PCO in 62 (28.84\%) patient; $44(32.35 \%)$ were in primary subfertility and $18(22.78 \%)$ in secondary subfertility group. Bilateral tubal block were present in $35(16.28 \%)$ patients; 23 $(16.91 \%)$ in primary and $12(15.19 \%)$ in secondary 
Table-I

Distribution of infertility patients according to their age $(n=215)$

\begin{tabular}{lcc}
\hline Age groupyears & Primary infertility $(\mathrm{n}=136)$ & Secondary infertily $(\mathrm{n}=79)$ \\
\hline $18-25$ & $56(41.18 \%)$ & $17(21.52 \%)$ \\
$26-35$ & $70(51.47 \%)$ & $52(65.82 \%)$ \\
$>35$ & $10(7.35 \%)$ & $10(12.66 \%)$ \\
\hline
\end{tabular}

Table-II

Distribution primary and secondary infertility patients according to laparoscopic findings

\begin{tabular}{lccc}
\hline Findings & $\begin{array}{c}\text { Primary Infertility } \\
\mathrm{n}=136(63.26 \%)\end{array}$ & $\begin{array}{c}\text { Secondary infertility } \\
\mathrm{n}=79(36.74 \%)\end{array}$ & Total $(\mathrm{n}=215)$ \\
\hline No visible abnormality & $22(16.18 \%)$ & $12(15.19 \%)$ & $34(15.81 \%)$ \\
Bilteral tubal block & $23(16.91 \%)$ & $12(15.19 \%)$ & $35(16.28 \%)$ \\
Unilateral tubal block & $25(18.38 \%)$ & $15(18.99 \%)$ & $40(18.60 \%)$ \\
PCO & $44(32.35 \%)$ & $18(22.78 \%)$ & $62(28.84 \%)$ \\
Endometriotic deposit,chocklate cyst & $15(11.03 \%)$ & $10(12.66 \%)$ & $25(11.63 \%)$ \\
PID,hydrosalphinx,TO mass & $7(5.15 \%)$ & $6(7.59 \%)$ & $13(6.05 \%)$ \\
Peritubal,periovarian adhesion & $24(17.65 \%)$ & $18(22.78 \%)$ & $42(19.53 \%)$ \\
Severe adhesion of uterus with surrounding structure & $5(3.68 \%)$ & $7(8.86 \%)$ & $12(5.58 \%)$ \\
Genital tract TB & $2(1.47 \%)$ & $1(1.27 \%)$ & $3(1.40 \%)$ \\
Fibroid & $11(8.09 \%)$ & $12(15.19 \%)$ & $23(\%)$ \\
Adenomyosis & $2(1.47 \%)$ & $1(1.27 \%)$ & $3(1.40 \%)$ \\
Ovarian cyst & $12(8.82 \%)$ & $14(17.72 \%)$ & $26(12.09 \%)$ \\
Unusual tortuous \& lengthy tube & $15(11.03 \%)$ & $9(11.30 \%)$ & $24(11.16 \%)$ \\
Mullerian agenesis\& hupoplasia & $3(2.21 \%)$ & & $3(1.40 \%)$ \\
Streak gonad & $1(0.74 \%)$ & & $1(0.47 \%) \circledast b$ \\
\hline
\end{tabular}

Table-III

Distribution of patients with primary and secondary infertility according to the treatment provided.

\begin{tabular}{lcc}
\hline Laparoscopic procedure & Primary infertility $(\mathrm{n}=136)$ & Secondary infertility $(\mathrm{n}=79)$ \\
\hline Ovarian drilling & $39(28.68 \%)$ & $13(16.46 \%)$ \\
Ovarian cystectomy & $14(10.29 \%)$ & $9(11.39 \%)$ \\
Adhesiolysis & $12(8.82 \%)$ & $10(12.66 \%)$ \\
Unilateral/Bilateral salphingostomy & $4(2.94 \%)$ & $1(1.27 \%)$ \\
Cyst puncture & $3(2.21 \%)$ & $4(5.06 \%)$ \\
Myomectomy & $2(1.47 \%)$ & $3(3.80 \%)$ \\
Laparoscopy followed by laparotomy for myomectomy & $4(2.94 \%)$ & $2(2.53 \%)$ \\
Laparoscopy followed by laparotomy for ovarian & $3(2.21 \%)$ & \\
cystectomy/unilateral salphingooophorectomy & & \\
\hline
\end{tabular}

sub fertile women. Unilateral tubal block were present in $40(18.60 \%)$ patients, $25(18.38 \%)$ in primary and $15(18.99 \%)$ in secondary patients respectively. Total $25(11.63 \%)$ patient had endometriosis (endometriotic deposit and chochlate cyst). $15(11.03 \%)$ in primary subfertile patient and $10(12.66 \%)$ in secondary subfertile patient. Total $13(6.05 \%)$ patients had hyrosalphinx, TO mass and PID; 7 (5.15\%) in primary subfertility, and $6(7.59 \%)$ in secondary infertility group. Peritubal and periovarian adhesion were present in 42 (19.53\%) patients; 24 (17.65\%) were in primary and $18(22.78 \%)$ were in secondary subfertile patient. Severe adhesion of uterus with surrounding structures were present in $12(5.58 \%)$ patients; $5(3.68 \%)$ in primary infertility and $7(8.86 \%)$ in secondary infertility group. POD obliterated in 14 
(6.51\%) patients; $7(5.15 \%)$ in primary and $7(8.86 \%)$ in secondary patients.

Laparoscopy has a great deal to offer an early diagnosis of abdominal tuberculosis and treatment. Genital tract tuberculosis were present in $3(1.40 \%)$ patients, $2(1.47 \%)$ in primary infertility and $1(1.27 \%)$ in secondary infertility group.

Total $23(10.70 \%)$ patients had Fibroid; $11(\%)$ in primary subfertile and $12(\%)$ in secondary subfertile patient. Adenomyosis was present in $3(1.40 \%)$ patients, $2(1.47 \%)$ in primary and $1(1.27 \%)$ in secondary subfertile patients. Ovarian cyst were present in $26(12.09 \%)$ patients, $12(8.82 \%)$ in primary subfertility and $14(17.72 \%)$ in secondary subfertility group.

Both tubes were found elongated and tortuous in 24 $(11.16 \%)$ patients; $15(11.03 \%)$ in primary subfertile patientt and $9(11.30 \%)$ in secondary subfertile patient. Hypoplasia of fallopian tube, uterus, cervix and mullerian agenesis present in $3(2.21 \%)$ primary and streak gonad present in one $(0.74 \%)$ primary subfertile group.

Various laparoscopic procedures were done at the same sitting like ovarian drilling done in $39(28.68 \%)$ patients in primary infertility , $13(16.46 \%)$ patients in secondary subfertile group. Adhesiolysis was done in $12(8.82 \%)$ patients in primary and $10(12.66 \%)$ patientsts in secondary infertile group. Ovarian cystectomy was done in $14(10.29 \%)$ patients of primary and $9(11.39 \%)$ patients of secondary group. Cyst puncture was done in $3(2.21 \%)$ and $4(5.06 \%)$ patientsts respectively. Unilateral and bilateral salphingostomy done in $4(\%)$ in primary subfertile patient and $1(\%)$ patient in secondary subfertile group. Laparoscpic myomectomy was done in 2 $(1.47 \%)$ primary subfertile patient. Laparotomy followed by myomectomy done in $4(2.94 \%)$ patient in primary and $3(3.80 \%)$ patients in secondary infertility group. Laparoscopy followed by laparotomy for ovarian cystectomy/unilateral salphingooophorectomy done in $3(2.21 \%)$ patients in primary and $2(2.53 \%)$ patients in secondary subfertile women.

\section{Discussion:}

The World Health organization (WHO) estimates that 60 to 80 million couples worldwide currently suffer from infertility. Infertility varies across regions of the world and is estimated to affect 8 to 12 percent of couples worldwide ${ }^{6}$.
Laparoscopy is a mandatory procedure for full assessment of the infertile couple ${ }^{1}$. Female age is the single most important determinant of spontaneous as well as treatment related conception. While there is no universally accepted definition of advanced reproductive age, 35 years is considered as the limit in infertility terms (American Society of Reproductive Medicine 2006) ${ }^{1}$.

It is widely accepted that infertility is a common medical problem. The role of laparoscopy in the diagnosis of primary and secondary infertility is established beyond any doubt ${ }^{2}$. Diagnostic laparoscopy is the standard means of diagnosing the tubal pathology, peritoneal factors, endometriosis and intra abdominal causes of infertility ${ }^{7}$. Endoscopic reproductive surgery intended to improve fertility may include surgery on the uterus, ovaries, pelvic peritoneum and the Fallopian tubes ${ }^{5}$. Endoscopc surgery fulfills the important microsurgical principles of gentle handling of tissue, constant irrigation, meticulous hemostasis and precise tissue dissection without the need for laparotomy ${ }^{5}$.

The prevalence of primary infertility in our study is $63.26 \%$ and of secondary infertility is $36.74 \%$. Usmani in Rawalpindi reported $62 \%$ of patients with primary infertility and $38 \%$ of patients with secondary infertility ${ }^{2}$. In our patients primary infertility presented earlier than secondary infertility. Same results were reported by Usmani who reported that patients with primary infertility presented earlier i.e. mean of 3.2 years than secondary infertility ${ }^{8}$.

In this study, normal pelvic findings and patent tubes on laparoscopy was found in $22(16.18 \%)$ cases of primary infertility and only in $12(12.19 \%)$ cases in secondary infertility.

The most commonly found pathologies cronologically were PCO, Peritubal and periovarian adhesion, Tubal block, endometriosis, ovarian cyst and fibroid in primary infertility. In secondary infertility, the common pathologies were cronologically PCO, Peritubal and periovarian adhesions, ovarian cyst, Tubal block, Fibroid and endometriosis .

Polycystic ovarian disease causes hormonal imbalance in women that is thought to be one of the leading causes of female infertility. PCO causes more than $75 \%$ of cases of anovulatory infertility. The prevalence of PCO in asymptomatic women is thought to be between 16 and $33 \%{ }^{3}$. The incidence 
of polycystic ovaries in our study was $32.35 \%$ in primary infertility and $22.78 \%$ in secondary infertility.

Tuboperitoneal factors accounts for up to $25-30 \%$ of infertility with varied and desired etiologies, pelvic peritoneal adhesion mostly sequels of prior infections from STD by Chlamydia trachomatics and N.gonorrhoea and post MR, abortion and delivery related to pelvic inflammatory disease(PID) ${ }^{9}$. Tubal occlusion, peritubal and periovarian adhesions are factors responsible for inhibition of ovum pick up and transport. In developed countries the major cause of tubal infertility is pelvic inflammatory disease ${ }^{2}$. We found incidence of bilateral tubal block in $16.91 \%$ and $15.19 \%$ and unilateral tubal block in $18.38 \%$ and $18.99 \%$ in primary and secondary subfertile women respectively. Peritubal and periovarian adhesions were present in $17.65 \%$ in case of primary infertility and $22.78 \%$ in case of secondary infertility that is in total $19.53 \%$ of cases. Duignan and Jordan reported peritubal and periovarian adhesions in $21.8 \%$ cases $^{10}$.

A single episode of PID carries upto $10 \%$ risk of future tubal factor infertility ${ }^{6}$. In our study PID, hydrosalphinx, TO mass were present in $5.15 \%$ and $7.59 \%$ in primary and secondary infertility respectively. In the study conducted by Raida $\mathrm{M}$ and co-workers, PID was found in $2.13 \%$ of primary and $5.08 \%$ of secondary infertility patients ${ }^{11}$.

Endometriosis affects $5-10 \%$ of the female population at reproductive age ${ }^{12}$. Endometriosis implantation mostly found in pelvic viscera and peritoneum ${ }^{13}$. in our study endometriosis was seen in $11.03 \%$ and $12.66 \%$ cases of primary and secondary infertility respectively. The study conducted by Mahmood showed incidence of endometriosis in $13.6 \%$ of patients in case of primary infertility and $2.52 \%$ in case of secondary infertility. In our study Incidence of adenomyosis were $1.47 \%$ and $1.27 \%$ in primary and secondary infertility group.

The incidence of myoma in women with infertility without any obvious cause of infertility is estimated to be $1-2.4 \% 5$. In our study, fibroids were seen in $8.09 \%$ and $15.19 \%$ cases of primary and secondary infertility respectively.

Ovarian cyst were present in $8.82 \%$ and $17.72 \%$ of primary and secondary infertility women. Unusally tortuous and lengthy tubes were present in $11.03 \%$ and $11.30 \%$ of primary and secondary infertility women.
Laparoscopy has a great deal to offer an early diagnosis of abdominal tuberculosis and treatment ${ }^{15}$. Genital tract tuberculosis is an important cause of infertility especially in endemic zones. Genital tuberculosis not only cause tubal obstruction and dysfunction but also impairs implantation due to endometrial involvement and ovulatory failure from ovarian involvement ${ }^{6}$. Our study revealed genital tract tuberculosis in $1.47 \%$ and $1.27 \%$ cases of primary and secondary infertilty respectively.

Congenital anomalies of the female reproductive system are associated with higher rate of infertility ${ }^{13}$. Mean prevalence of uterine malformation in general population and in the population of fertile women is approximately $4.3 \%$, in infertile patients approximately $3.5 \%{ }^{16}$. In our study, mullerian agenesis and hypoplasia seen in $2.21 \%$ and streak gonad seen in $0.74 \%$ primary infertility cases.

Various laparoscopic procedures were done at the same sitting like Ovarian drilling done in $28.68 \%$ patients in primary infertility, $16.46 \%$ patients in secondary subfertile group. Adhesiolysis done in $8.82 \%$ patients in primary and $12.66 \%$ patients in secondary infertile group. Ovarian cystectomy done in $10.29 \%$ patients of primary and $11.39 \%$ patients of secondary group. Cyst puncture done in $2.21 \%$ and $5.06 \%$ patients respectively. Unilateral and bilateral salphingostomy done in $2.94 \%$ in primary subfertile patient and $1.27 \%$ patient in secondary subfertile group. Laparoscopic myomectomy done in $1.47 \%$ primary subfertile patient. Laparoscopyt followed by laparatomy for myomectomy done in $2.94 \%$ patient in primary and $3.80 \%$ patients in secondary infertility group. Laparoscopy followed by laparotomy for ovarian cystectomy, unilateral salphingooophorectomy done in $2.21 \%$ patients in primary and $2.53 \%$ patients in secondary subfertile women.

\section{Conclusion:}

Laparoscopic procedures are less invasive, more convenient and more precise for diagnosis and treatment of infertile women.

Laparoscopy by direct visualization of pelvic structures facilitates identification of etiology which commonly includes endomtriosis, adhesions, tubal block, ovarian cysts or pelvic inflammatory diseases, so that therapeutic intervention can be initiated, while avoiding potentially ineffective or unnecessary 
empiric medical treatment for ovulation induction. In some patients, diagnostic laparoscopy alters treatment plans, including earlier utilization of assisted reproductive technology. It is essential that the surgeon performing the procedure is properly trained and experienced in laparoscopy. The patient has to be properly counseled that and all the known complication and possible treatment discussed.

\section{References:}

1. Krishna C, Prathima S, Chandraiah S, Anitha G.S. Laparoscopy as a diagnostic tool in evaluation of female factors in infertility. International Journal of Reproduction, Contraception, Obstetrics and Gynecology.2017 Mar;6(3):864-867.

2. Haider G, Rani S et al. Laparoscopic Evaluation of Female Infertility. J Ayub Med Coll Abbottabad 2010;22(1).

3. Aruna Reddy G, Anita H, Swarupa Rani A, Anupama H. Laparoscopic evaluation of female factors in infertility. MRIMS Journal of Health Science 2016;. 4 (3):155-157.

4. MalikA, Iqbal S. Role of Laparoscoy in infertility. JK- Practitioner 2013; (1-2): 48-49.

5. Berker B, Madhavi A et al. Role of Laparoscopic surgery in infertility. Middle East Fertility Society Journal 2005;10(2):94-104.

6. Wani Q A, Ara R et al. Diagnostic laparoscopy in the Evaluation of Female Factors in infertility in Kashmir Valley. Int J Women's Health Reproduction Sci Vol.2, Winter 2014 Supplement ISSN 2330-4456. .

7. Chimote A, Samal S et al. Laparoscopy and hysterectomy in patients of infertility in a rural set up. Int J Reprod Contracep Obstel Gynecol. 2015 Apr;4(2):322-328.

8. Usmani AT, Shaheen F, Waheed N. Laparoscopic evaluation of female infertility. Pak Armed Forces Med J 1995;45(2):63-5.

9. Nahar S, Jahan D, Akter N, Das B. Laparoscopic evaluation of tubo-peritoneal causes of infertility. Bang Med J Khulna 2013;46:16-20.

10. Rana T. Role of laparoscopy in gynaecologic diagnosis.Pak j Obstel Gynecol 1992;5(2):31.

11. Al-Wazzan R.M, Jabbar E. Diagnostic laparoscopy in female infertility. Ann. Coll. Med. Mosul. 2009;35(1):58-64.

12. Jozwiak AS, Ciebiera M et al. Effectiveness of laparoscopic surgeries in treating infertility related to endometriosis. Annals of Agricultural and environmental Medicine 2015;22(2): 329-331.

13. Salehpour $\mathrm{S}$, Zhaam $\mathrm{H}$ et al. Evaluation of Diagnostic Visual Findings at Laparoscopy in Endometriosis. Iranian Journal of Fertility and Sterility. Nov-Dec 2007;1(3):123-126.

14. Millingos S, Protopapas A, Kallipolitis G, Drakakis $P$ et al. Laparoscopic evaluation of infertile patients with chronic pelvic pain. Reprod Biomed Online, 2006;12(3):347-53.

15. Prasad S, Jain S, Prakash A, Gautom A et al. Evaluation of efficacy of laparoscopy in patients with chronic abdominal pain. International Surgery Journal.2017 Jun;4(6):1856-1860.

16. Godinjak Z, Idrizbegovic E. Should Diagnostic Hysteroscopy be a routine procedure during diagnostic Laparoscopy in Infertile Women? Bosnian Journal of Basic Medical Sciences 2008;8(1)44-47. 